\title{
Improvement of production arrangement chart for mechanised longwall at Seam 11 of Centre area - Duong Huy coal mine
}

\author{
Hiep Hoang Do ${ }^{1}$, Tung Manh Bui ${ }^{2,}$, Dung Tien Thai Vu ${ }^{2}$, Anh Tuan \\ Tran ${ }^{3}$ \\ ${ }^{1}$ Company 35 - Dong Bac Corporation, Quang Ninh, Vietnam \\ ${ }^{2}$ Hanoi University of Mining and Geology, Hanoi, Vietnam \\ ${ }^{3}$ Vietnam National Coal - Mineral Industries Holding Corporation Limited, Hanoi, Vietnam
}

ARTICLE INFO ABSTRACT

\section{Articlehistory:}

Received $12^{\text {th }}$ Feb. 2021

Revised 14th May 2021

Accepted 15 ${ }^{\text {th }}$ June 2021

Keywords:

Duong Huy coal mine,

Mechanized longwall face,

Production arrangement chart,

Working time.
The mechanization of longwall mining is an inevitable trend in underground coal industry. At present, Vietnam has operated many mechanized longwall faces in Quang Ninh coal field. The mechanised longwall at Seam 11, Centre area Duong Huy coal mine has been operated and its mechanised equipment complex basically performs as designed. However, the actual production shows that the longwall equipment has not reached its maximum capacity while the arrangement of production remains inadequate. Apart from objective factors, the initial production arrangement chart did not consider the maximization of the mechanised complex. In this paper, the authors used field observation and theoretical methods for improvement of production arrangement chart for the mechanised longwall at Seam 11, Duong Huy coal mine. An improved chart of production arrangement (and subsequently a chart of labour arrangement) has been developed based on actual time cost for each production task. According to the new chart, the production can be now implemented with 7 cuts per day - night. This arrangement well corresponds with practical production capacity that increases the longwall productivity.

Copyright (C) 2021 Ha noi University of Mining and Geology. All rights reserved.

${ }^{*}$ Correspondingauthor

E - mail: buimanhtung@humg.edu.vn

DOI:10.46326/JMES.2021.62(5a).08 


\title{
Tạp chí Khoa học Kỹ thuật Mỏ - Địa chất
}

Trang điện tữ: http://tapchi.humg.edu.vn

\section{Nghiên cứu hoàn thiện biểu đồ tổ chức sản xuất lò chợ cơ giới hóa vỉa 11 khu Trung tâm - Mỏ than Dương Huy}

\author{
Đỗ Hoàng Hiệp ${ }^{1}$, Bùi Mạnh Tùng 2,* Vũ Thái Tiến Dũng ${ }^{2}$, Trần Tuấn Anh ${ }^{3}$ \\ ${ }^{1}$ Công ty 35 - T ổng công ty Đông Bắc, Quảng Ninh, Việt Nam \\ 2 Trường Đại học Mỏ - Địa chất, Hà Nội, Việt Nam \\ 3 Tập đoàn Công nghiệp Than - Khoáng sản Việt Nam, Hà Nội, Việt Nam
}

THÔNG TIN BÀI BÁO

Quá trình:

Nhận bài $12 / 02 / 2021$

Sửa xong $14 / 5 / 2021$

Chấp nhận đăng 15/6/2021

Tù̀ khóa:

Biểu đồ tổ chức sản xuất,

Dương Huy,

Hoàn thiện,

Lò chợ cơ giới hóa,

Thời gian làm việc.
TÓMTẮT

Công nghệ cơ giới hóa trong khai thác than lò chợ là một xu hướng tất yếu trong ngành khai thác mỏ hầm lò. Hiện nay, Việt Nam đã có nhiều mỏ hầm lò vùng Quảng Ninh áp dụng công nghệ cơ giới hóa đồng bộ vào khai thác than lò chơ. Tai mỏ than Dương Huy đã lắp đặt công nghẹ cơ giới hóa vào khai thác lò chợ vỉa 11 khu Trung tâm. Lò chợ này đến nay đã đi vào hoạt động, tổ hợp thiết bi cơ giới hóa lò chợ co bản đáp úng được theo thiết kế ban đầu. Tuy nhiên, thực tế sản xuất ở lò chợ cho thấy, công suất của các thiết bi chưa phát huy tối đa hiệu quả, công tác tổ chức lò chợ còn nhiều bất cập, do đó hiệu quả và năng suất còn thấp. Ngoài nhũng yếu tố khách quan, biểu đồ tổ chức sản xuất của lò chợ ban đầu theo thiết kếc chưa tính đến việc phát huy tối đa năng lực của các thiết bi trong tổ hợp cơ giới hóa.Trong bài báo này, nhóm tác giả đã sủ dụng phương pháp phân tích lý thuyết kết hợp quan trắc tại hiên truờng sản xuất, tiến hành nghiên cúu hoàn thiện biểu đồ tổ chức sản xuất cho lò chơ cơ giới hóa vỉa 11 khu Trung tâm - mỏ than Dương Huy. Biểu đồ tổ chức sản xuất và bố trí nhân lực mới được thiết kế dựa trên các chi phí thò̀i gian thực tế thực hiện tùng cồng đoạn sả̉n xuất. Từ đó đã đề xuất áp dụng với 7 luồng khấu/ngày - đêm, phù hợp với năng lực sản xuất thực tế, gia tăng đáng kể công suất của lò chợ.

\section{Mởđầu}

Lò chợ cơ giới hóa là một trong những công nghệ tiên tiến trong ngành công nghiệp khai thác than hiện nay. Áp dụng các công nghệ cơ giới hóa trong khai thác than hầm lò nhằm mục đích đảm

*Tác giả liên hệ

E - mail: buimanhtung@humg.edu.vn DOI:10.46326/JMES.2021.62(5a).08 bảo an toàn, nâng cao sản lượng, giảm tổn thất tài nguyên và giảm thiểu ảnh hưởng đến môi trường xung quanh (Rakesh Kumar và nnk., 2015; Dung Tien Le và nnk., 2018). Đây là một trong những định hướng cơ bản cho sự phát triển bền vững của ngành khai thác than hầm lò ở Việt Nam nói riêng và trên thế giới nói chung. Việc lựa chọn loại hình công nghệ cơ giới hóa phù hợp để đưa vào thực tế sản xuất cần phải được nghiên cứu dựa trên các yếu tố điều kiện địa chất đặc thù tương ứng với 
từng khu vực khai thác cụ thể. Việc bố trí biểu đồ tổ chức sản xuất của lò chợ sẽ phụ thuộc vào nhiều yếu tố đầu vào như: khả năng bố trí nhân lực, năng suất yêu cầu của lò chợ, loại thiết bị sử dụng (Lê Duy Khánh, 2019).

Là một trong số không nhiều mỏ than tại Việt Nam hiện nay có điều kiện áp dụng phù hợp, Công ty than Dương Huy đã nghiên cứu và đầu tư công nghệ cơ giới hóa đồng bộ cho lò chợ tại vỉa 11 khu Trung tâm. Mặc dù đã đi vào hoạt động nhưng lò chợ chưa đạt được công suất như thiết kế ban đầu do sự chưa phù hợp của biểu đồ tổ chức sản xuất với điều kiện thực tế sản xuất (Công ty than Dương Huy - TKV, 2020). Chính vì vậy, cần thiết phải nghiên cứu điều chỉnh kịp thời, linh hoạt trong việc xây dựng, hoàn thiện từng bước biểu đồ tổ chức sản xuất cho lò chợ, nhằm mục đích gia tăng hiệu quả sản xuất, đáp ứng nhu cầu thực tế trong giai đoạn sắp tới.

\section{2. Đặc điểm điều kiện địa chất - kỹ thuật khu vực lò chợ cơ giới hóa}

Lò chợ cơ giới hóa được thiết kế đưa vào khai thác tại vỉa 11 khu trung tâm với chiều dày vỉa $0,28 \div 7,52 \mathrm{~m}$, trung bình $3,09 \mathrm{~m}$, vỉa tương đối ổn định. Cấu tạo vỉa tương đối phức tạp, thường có từ $0 \div 5$ lớp đá kẹp, chiều dày đá kẹp từ $0 \div 1,84 \mathrm{~m}$, trung bình $0,14 \mathrm{~m}$. Các lớp đá kẹp trong vỉa chủ yếu là sét kết, bột kết, đôi chỗ là sét than. Góc dốc vỉa thay đổi từ $9 \div 75^{0}$, trung bình $26^{0}$. Đá vách, trụ vỉa chủ yếu là sét kết, sét kết chứa than mỏng hoặc bột kết chuyển tiếp dần sang cát kết dày. Tổ hợp lò chợ cơ giới hóa được đưa vào hoạt động tại các lò chợ vỉa 11 khu Trung tâm bao gồm: máy khấu than MG300/700 - WDK; máng cào SGZ730/220; giàn chống giữa lò chợ ZY3200/16/36 và giàn chống quá độ ZYG3200/16/36 (Công ty than Dương Huy - TKV, 2020). Lò chợ có chiều dài trung bình $125 \mathrm{~m}$, công suất theo thiết kế ban đầu là $600.000 \mathrm{~T} /$ năm, tuy nhiên sau đó được điều chỉnh xuống còn $350.000 \div 400.000 \mathrm{~T} /$ năm. Sơ đồ chuẩn bị lò chợ vỉa 11 khu Trung tâm mỏ than Dương Huy được thể hiện trên Hình 1.

\section{Phân tích hiện trạng biểu đồ tổ chức sản xuất}

Công tác tổ chức sản xuất tại lò chợ theo thiết kế được bố trí $3 \mathrm{ca} / \mathrm{ngày} \mathrm{-} \mathrm{đêm.} \mathrm{Tiến} \mathrm{độ} \mathrm{khấu} \mathrm{than}$ trung bình đạt khoảng 3,15 m/ngày - đêm tương ứng với 5 luồng khấu. Theo biểu đồ tổ chức sản xuất của lò chợ (Hình 2), ca 1, 2 mỗi ca khấu 2 luồng, ca 3 khấu 1 luồng và bảo dưỡng thiết bị (Công ty than Dương Huy - TKV, 2020).

Qua khảo sát thực tế, quá trình khấu chống tại lò chợ còn một số bất cập như: thời gian hữu ích thực hiện các công đoạn còn thấp, thời gian gián đoạn trong quá trình thực hiện các công việc còn lớn, chưa phù hợp. Các thiết bị được lựa chọn chưa đạt được hiệu quả cao do thực tế chưa tạo được mối quan hệ hợp lý về mặt không gian và thời gian giữa các thiết bị cấu thành tổ hợp cơ giới hóa cũng như giữa các công đoạn cấu thành chuỗi hoạt động sản xuất của lò chợ, điển hình như máy khấu của lò chợ đang hoạt động với tốc độ thấp hơn nhiều so với tốc độ thiết kế.

Do vậy, để đẩy nhanh tiến độ, tăng sản lượng khai thác, cần phải nâng cao hơn nữa tính đồng bộ thiết bị của tổ hợp cơ giới hóa, tức là phải tính toán, xây dựng và hoàn thiện lại công tác tổ chức sản xuất để mang lại hiệu quả thực tế cao hơn.

\section{Hoàn thiện biểu đồ tổ chức sản xuất cho lò chợ cơ giới hóa mỏ than Dương Huy}

Biểu đồ tổ chức sản xuất được xây dựng trên cơ sở tính toán, xác định khối lượng và thời gian thực hiện của từng công đoạn sản xuất chính trong suốt không gian chiều dài của lò chợ. Công tác khấu gương và công tác di chuyển vì chống và máng cào là 2 công đoạn chủ yếu, đóng vai trò quyết định đến trạng thái hoạt động của các thiết bị trong tổ hợp lò chợ cơ giới hóa (Victor và nnk., 2013; Syd và nnk., 2019; Joachim Pielot, 2006; Yun và nnk., 2003). Vì vậy, cần phải xác định chi phí thời gian hợp lý cho từng công việc trên trong điều kiện thực tế của các lò chợ cơ giới hóa vỉa 11 khu Trung tâm - mỏ than Dương Huy.

\subsection{Xác định chi phí thò̀i gian cho công tác khấu gương}

Công tác khấu gương trong lò chợ cơ giới hóa được thực hiện bằng máy khấu MG300/700 WDK có tốc độ di chuyển theo đặc tính kỹ thuật của máy từ $0 \div 8,2 \mathrm{~m} /$ phút. Tuy nhiên, tốc độ di chuyển có tải của máy khấu trong thực tế khai thác sẽ được xác định trên các cơ sở: đặc điểm cấu tạo vỉa, độ kiên cố của than, số lượng, tính chất và độ cứng đá kẹp trong vỉa than; góc dốc lò chợ, độ ổn định của vách, trụ vỉa than. 


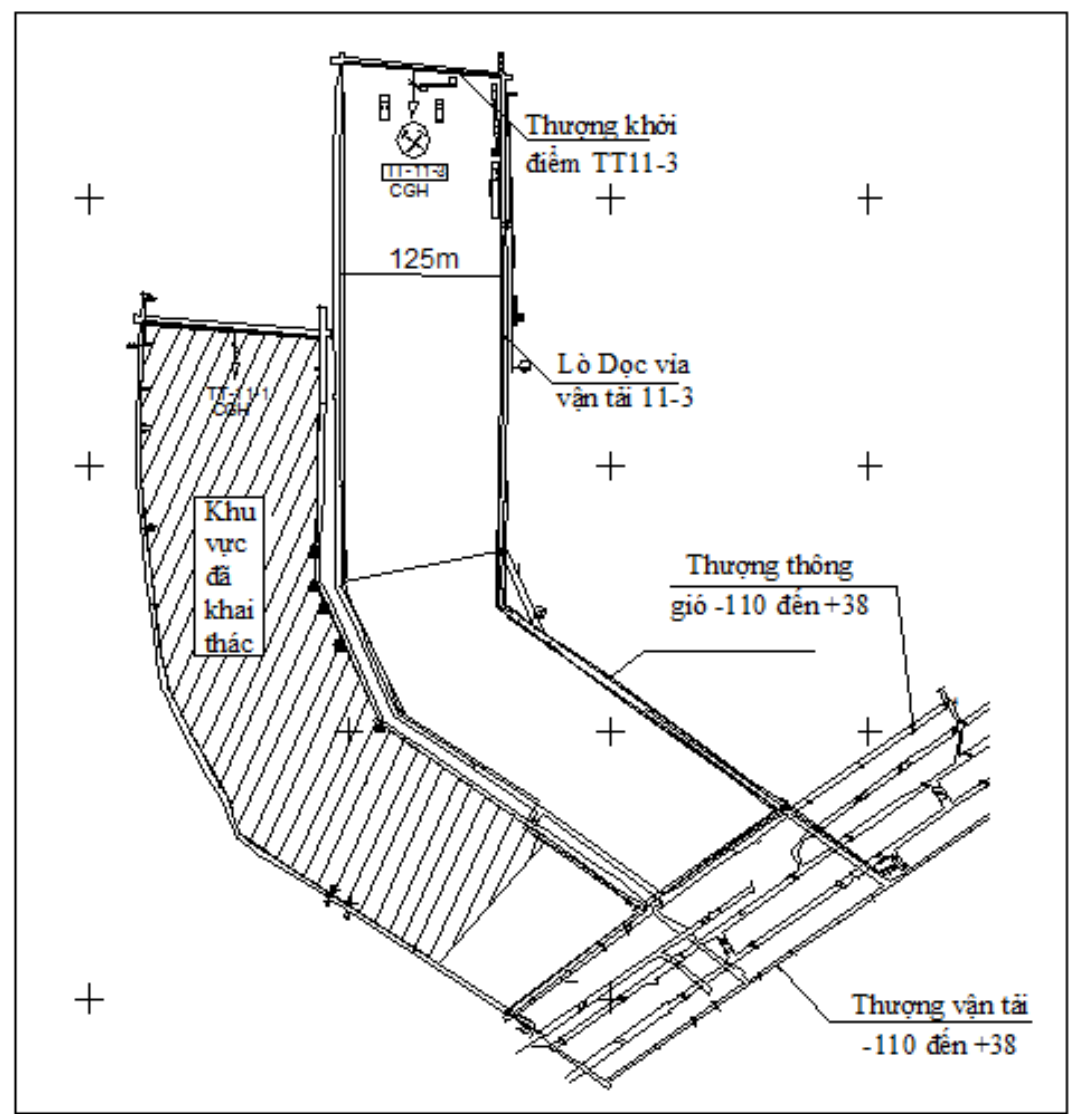

Hình 1. Sơ đồ chuẩn bị lò chợ cơ giói hóa vỉa 11 khu Trung tâm mỏ than Dưong Huy.

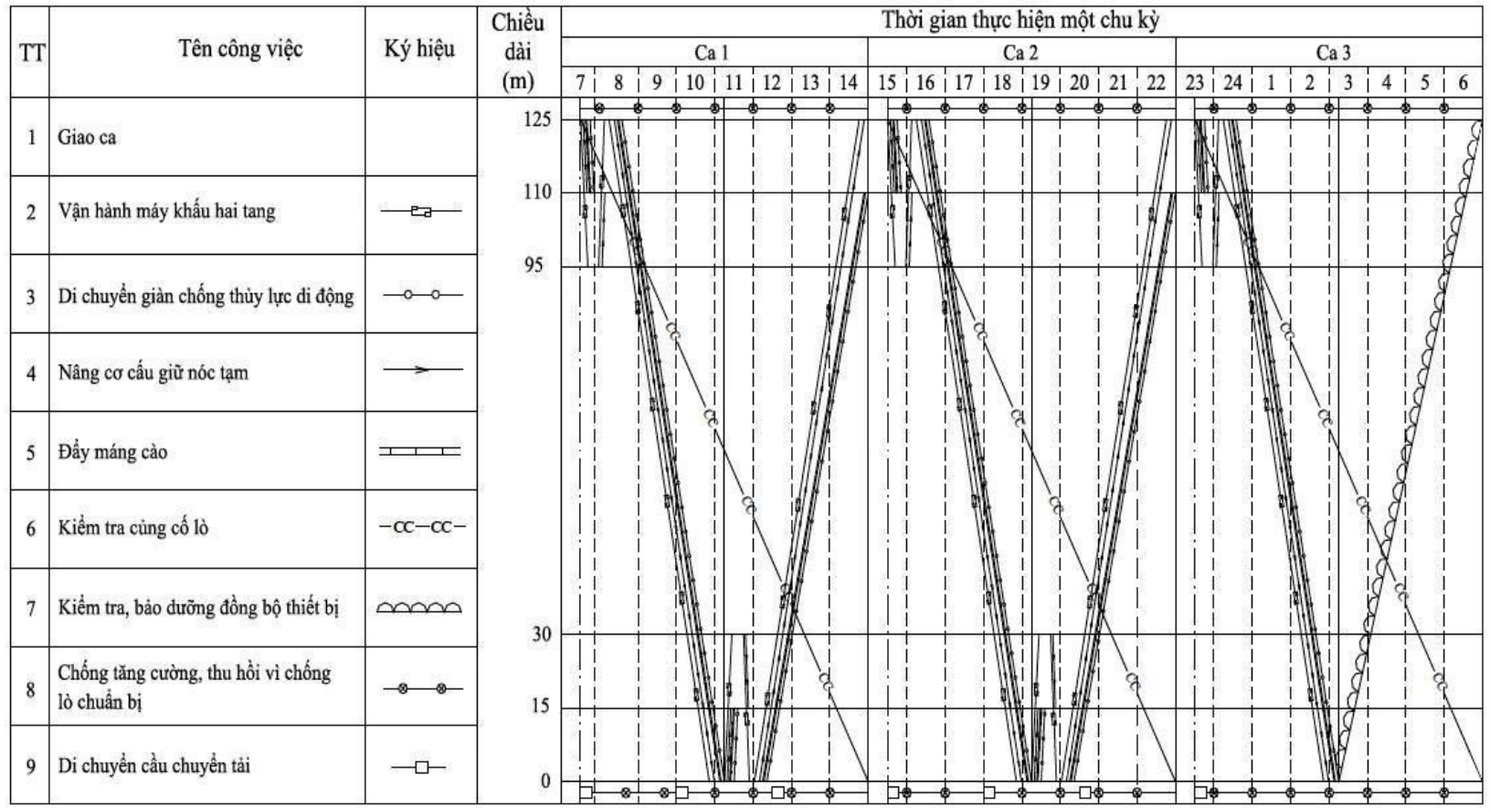

Hình 2. Biểu đồ tổ chức sản xuất của lò chợ cơ giới hóa vỉa 11 khu Trung tâm (Công ty than Dưong Huy - TKV, 2020). 
Trước khi bắt đầu luồng khấu mới, cần thực hiện khấu tạo khám tại vị trí tiếp giáp lò đầu hoặc lò chân của lò chợ. Quá trình khấu khám được thực hiện như sau:

- Khi máy khấu đến đầu (hoặc chân) lò chợ, sẽ thực hiện công tác tạo luồng khấu mới bằng cách quay chuyển vị trí tang cắt: tang cắt trước đang khấu phần nóc hạ xuống để khấu phần nền và ngược lại tang khấu sau nâng lên khấu phần nóc; hành trình máy khấu theo hướng ngược lại xuống phía dưới (hoặc lên trên), khấu luồng mới với chiều dài 30 m tương đương chiều dài khám;

- Sau khi khấu được $30 \mathrm{~m}$ khám, tiến hành đảo chiều tang khấu và cho máy khấu di chuyển ngược lại khấu nốt phần than sát nền để tạo khám hoàn chỉnh.

Như vậy, thời gian khấu khám được xác định theo công thức:

$$
T_{k}=\frac{2 \times L_{k}}{v_{m k}}+\frac{L_{g}}{v_{k k}}, \text { phút }
$$

Trong đó: $L_{k}$ - chiều dài khám, $L_{k}=30 \mathrm{~m} ; v_{m k}$ tốc độ khấu của máy khấu, $v_{m k}=3,0 \mathrm{~m} /$ phút; $v_{k k}$ tốc độ di chuyển của máy khấu khi không khấu, $v_{k k}$ $=6,0 \mathrm{~m} /$ phút.

$$
T_{k}=25 \text { phút }
$$

Thời gian khấu phần gương còn lại lò chọ:

$$
T_{g}=\frac{L_{g}}{v_{m k}}, p h u ́ t
$$

Trong đó: $L_{g}$ - chiều dài còn lại của lò chợ không tính phần khám đã khấu, $L_{g}=95 \mathrm{~m}$.

$$
T_{g}=31,6 \text { phút }
$$

Trong khoảng thời gian máy khấu hoạt động trong 1 luồng khấu, máy khấu phải chuyển hướng 2 lần với thời gian ngừng chuyển hướng, thay răng cắt trung bình 7 phút/lần. Vì vậy, tổng thời gian cần thiết để máy khấu hoàn thiện 1 luồng khấu là:

$$
\begin{gathered}
T_{1}=25+31,6+2 \times 7=70,6 \text { phút } \\
T_{1}=70 \text { phút }
\end{gathered}
$$

\subsection{Xác định chi phí thò̀i gian cho công tác di chuyển máng cào và giàn chống}

Công tác di chuyển máng cào và giàn chống thực hiện nối tiếp trong quá trình máy khấu khấu gương: di chuyển giàn chống được thực hiện dứt điểm từng giàn, di chuyển giàn nào thì hạ thấp giàn (giảm tải) đó và được thực hiện ngay sau khi di chuyển máng cào, bao gồm hạ tấm chắn gương, thu rút hết hành trình pít tông kéo giàn tịnh tiến sát vào máng cào vừa di chuyển (bước di chuyển bằng bước khấu), sau đó nâng giàn (chất tải).

Thời gian di chuyển phụ thuộc vào công tác tổ chức sản xuất trong không gian lò chợ và tay nghề thực tế của công nhân thực hiện. Qua khảo sát tại một số lò chợ cơ giới hóa tại các mỏ Vàng Danh, Nam Mẫu, Khe Chàm và Dương Huy, thời gian thực tế để di chuyển máng cào và giàn chống thường đạt 1 phút/m chiều dài lò chợ. Đối với các vị trí ngã ba khu vực khám đầu và chân, thời gian di chuyển thường tăng lên 1,5 phút/m chiều dài lò chợ, do có sự gia tăng về áp lực tại các khu vực này.

Để đơn giản trong công tác tính toán, có thể coi việc di chuyển máng cào trong 1 luồng khấu mới sẽ được bắt đầu tại vị trí cách máy khấu hoạt động bằng đúng chiều dài khám. Công tác di chuyển giàn chống được tiến hành đồng thời với công tác di chuyển máng cào. Với tốc độ di chuyển như trên thì vị trí hoạt động của máy khấu luôn vượt trước vị trí di chuyển máng cào và giàn chống một khoảng cách > $30 \mathrm{~m}$, điều này đảm bảo công tác di chuyển máng cào và giàn chống không chịu ảnh hưởng tiêu cực từ công tác khấu gương.

Như vậy, thời gian để thực hiện công tác di chuyển máng cào và vì chống tính từ lúc bắt đầu luồng khấu mới có thể được tính theo công thức:

$$
T_{2}=T_{k}+\frac{L_{k}}{1,5}+\frac{L_{g}}{1}, \text { phú } t
$$

Thay số vào ta được $T_{2}=140$ phút

\subsection{Xác định chi phí thò̀i gian cho 1 luồng khấu}

Theo tính toán, thời gian khấu gương $\mathrm{T}_{1}=70$ phút nhỏ hơn nhiều so với thời gian di chuyển máng cào và giàn chống $\mathrm{T}_{2}=140$ phút. Như vậy, sau khi hoàn thành khấu gương, máy khấu sẽ có khoảng thời gian 70 phút dành cho công tác sửa chữa, bảo dưỡng trước khi công tác di chuyển máng cào và giàn chống hoàn thành. Tính đến cả thời gian bảo dưỡng động cơ máng cào 10 phút/luồng khấu cuối mỗi chu kỳ di chuyển thì tổng thời gian hoàn thành công tác khấu chống và bảo dưỡng của 1 luồng khấu là:

$$
T_{l k}=\max \left(T_{1}, T_{2}\right)+10=140+10=150 \text { phút } .
$$




\subsection{Xây dụng biểu đồ tổ chức sản xuất và bố trí nhân lực}

Hiện tại, các mỏ than hầm lò Việt Nam đang thực hiện theo chế độ 3 ca sản xuất/ngày - đêm với mỗi ca kéo dài 8 tiếng. Không tính đến thời gian giao ban đầu ca, thời gian làm việc thực tế của công nhân được tính là 7,5 tiếng $=450$ phút.

Như vậy, số luồng khấu tối đa có thể thực hiện hoàn chỉnh trong 1 ca sản xuất là:

$$
N_{l k}=450 / T_{l k}=450 / 150=3 \text { luồng khấu } / c a
$$

Từ các tính toán ở trên, có thể thành lập được biểu đồ sản xuất mới, phù hợp hơn với điều kiện thực tế của lò chợ, thực hiên khấu 2 ca, đầu mỗi ca khấu 3 luồng, ca thứ 3 khấu 1 luồng, thời gian còn lại để củng cố bảo dưỡng thiết bị và xử lý các sự cố phát sinh chung. Biểu đồ tổ chức sản xuất và bố trí nhân lực được xây dựng mới thể hiện trên các Hình 3, 4.

Với việc tính toán hoàn thiện lại các thông số chi phí thời gian cho các công đoạn sản xuất chính của lò chợ cơ giới hóa vỉa 11 khu Trung tâm - Công ty than Dương Huy có thể thấy, trong điều kiện thông thường mỗi ca sản xuất thực hiện được 3 luồng khấu. Số lượng luồng khấu được hoàn thiện ở mức 7 luồng khấu/ngày - đêm so với mức 5

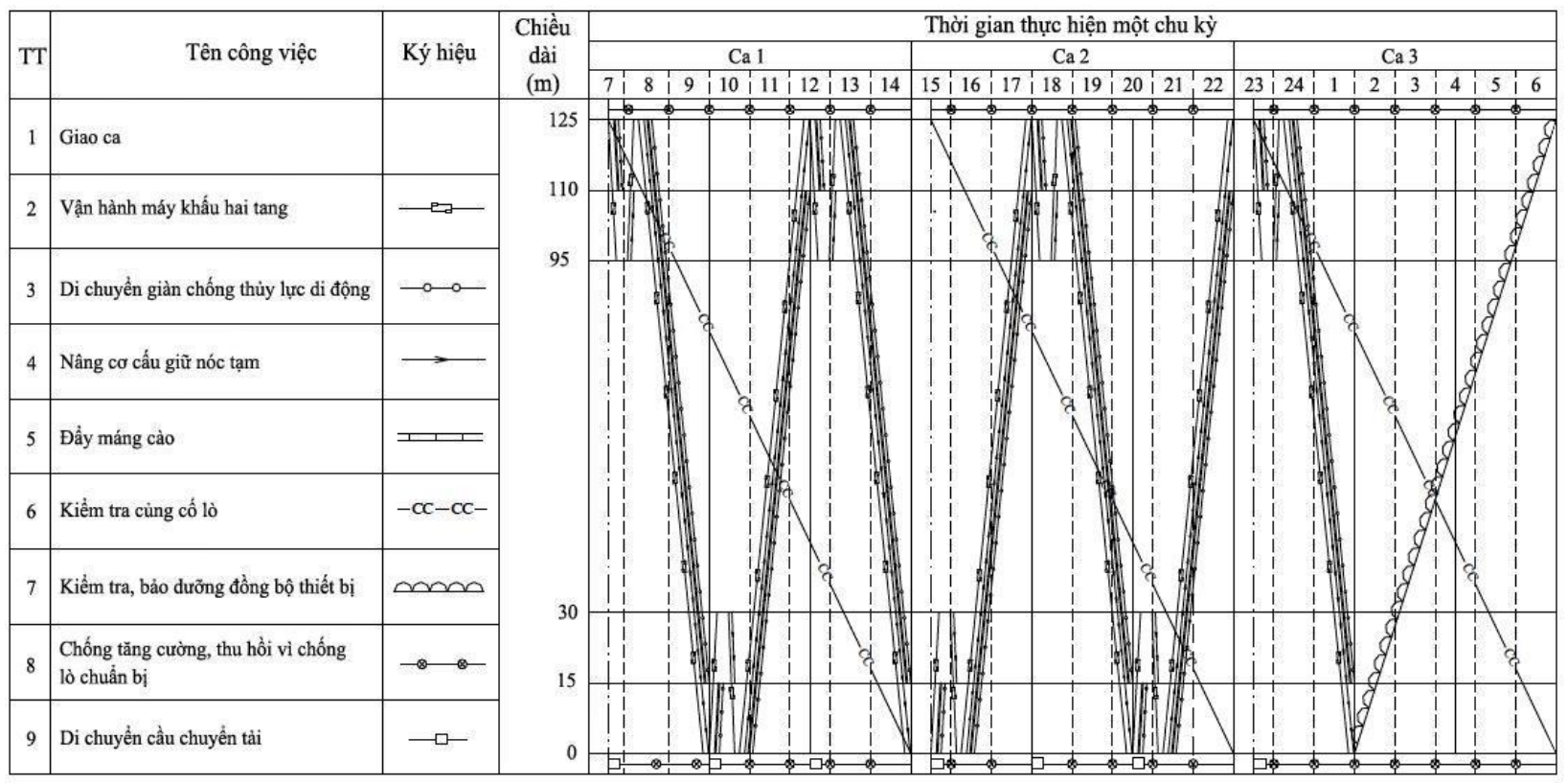

Hình 3. Biểu đồ tổ chức sản xuất lò chợ cơ giới hóa sau khi hoàn thiện (7 luồng khấu/ngày - đêm).

\begin{tabular}{|c|c|c|c|c|c|c|c|c|c|c|c|c|c|c|c|c|c|c|c|c|c|c|c|c|c|c|c|}
\hline \multirow{3}{*}{ TT } & \multirow{3}{*}{ Tên công việc } & \multicolumn{4}{|c|}{ Nhân lực } & \multicolumn{22}{|c|}{ Thời gian thực hiện một chu kỳ } \\
\hline & & \multicolumn{3}{|c|}{ Thứ tự ca } & \multirow{2}{*}{$\Sigma$} & \multicolumn{8}{|c|}{$\mathrm{Ca} 1$} & \multicolumn{7}{|c|}{$\mathrm{Ca} 2$} & \multicolumn{7}{|c|}{ Ca 3} \\
\hline & & I & II & III & & 7 & 8 & 9 & 10 & 11 & & 13 & 14 & 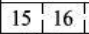 & 17 & 18 & & 20 & \begin{tabular}{l|l}
21 & 22 \\
21 &
\end{tabular} & 222 & \begin{tabular}{l|l|l|}
23 & 24 \\
\end{tabular} & 1 & 2 & 3 & 4 & 5 & 6 \\
\hline 1 & Giao ca & & & & & $-\prod_{11}^{1}$ & & & iil & & & & & $\begin{aligned} 1 \\
1\end{aligned}$ & & i & & Iil| & & - & & & & & & & \\
\hline 2 & Kiểm tra, củng cố lò & 2 & 2 & 2 & 6 & $\frac{11}{\pi 1}$ & & & & & & & & & & & & & & & & & & & & & \\
\hline 3 & Vận hành máy khấu hai tang & 4 & 4 & 4 & 12 & & & & & & & & & & & & & & & & & & & & & & \\
\hline 4 & Nâng cơ cấu giữ tạm nóc & 1 & 1 & 1 & 3 & & & & $\sqrt{1}$ & & & & & & & & & & & & & & & & & & \\
\hline 5 & Đầy máng cào, di chuyền giàn chống & 4 & 4 & 4 & 12 & the & & & 要 & & int & & & & & the & & 业 & & & | & 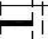 & & & & & \\
\hline 6 & Vận hành bơm DD nhũ hoa, bơm sương mù & 2 & 2 & 2 & 6 & & & & & & & & & & & & & & & & & & & & & & \\
\hline 7 & Vận hành máng cào lò chợ & 2 & 2 & 2 & 6 & & & & & & & & & & & & & & & & & & & & & & \\
\hline 8 & Vận hành máy chuyển tải, máy nghiền & 1 & 1 & 1 & 3 & & & & & & & & & & & & & & & & & & & & & & \\
\hline 9 & Phụ trách bơm thoát nước lò chợ, các lò dọc via & 2 & 2 & 2 & 6 & & & & & & & & & & & & & & & & & & & & & & \\
\hline 10 & Chống tăng cường, thu hồi vì chống đầu lò chợ & 3 & 3 & 3 & 9 & & & & & & & & & & & & & & & & & & & & & & \\
\hline 11 & Chống tăng cường, thu hồi vì chống chân lò chọ & 3 & 3 & 3 & 9 & & & & & & & & & & & & & & & & & & & & & & \\
\hline 12 & Chuyền vật liệu & 2 & 2 & 2 & 6 & & & & & & & & & & & & & & & & & & & & & & \\
\hline 13 & Trực cơ điện, thủy lực & 2 & 2 & 2 & 6 & & & & & & & & & & & & & & & & & & & & & & \\
\hline 14 & Kiểm tra, bảo dưỡng thiết bị đồng bộ & - & -1 & (11) & (11) & & & & & & † & & & & & & & i & & & $\prod_{1}^{11}$ & & & & & & \\
\hline \multirow[t]{2}{*}{15} & Chi đạo sản xuất & 3 & 2 & 2 & 7 & H & & & & & $\frac{1}{1}$ & & & - & & & & & & & & & & & & & \\
\hline & Tổng cộng & 31 & 30 & 30 & 91 & $i$ & & & & & 1 & & & j & & & & & & & il & & & & & & \\
\hline
\end{tabular}

Hình 4. Biểu đồ bố trí nhân lực lò chợ cơ giới hóa sau khi hoàn thiện (7 luồng khấu/ngày - đêm). 
luồng khấu/ngày - đêm đang áp dụng ở lò chợ. Điều này dẫn đến sự gia tăng sản lượng của lò chợ ở mức 140\% so với thiết kế ban đầu.

\section{Kết luận}

Thông qua việc nghiên cứu hoàn thiện công tác tổ chức sản xuất của lò chợ cơ giới hóa vỉa 11 khu Trung tâm - mỏ than Dương Huy, dựa trên các thông số thời gian thực hiện các công đoạn sản xuất chính, nhóm tác giả đã xây dựng được biểu đồ tổ chức mới tương ứng với khả năng làm việc của tổ hợp thiết bị và tay nghề công nhân trong thực tế sản xuất. Với việc gia tăng số lượng luồng khấu lên 7 luồng/ngày - đêm, nâng cao công suất của lò chợ cơ giới hóa khi được áp dụng.

Nghiên cứu được thực hiện dựa trên các thông số kỹ thuật cụ thể thu thập được, trong thực tế có thể xuất hiện những yếu tố khách quan ảnh hưởng trực tiếp đến hiệu quả sản xuất của lò chợ cơ giới hóa mà trong quá trình xây dựng biểu đồ không tính đến do các yếu tố ảnh hưởng không mang tính chu kỳ, ví dụ như: thay đổi về điều kiện địa chất, sự cố hỏng hóc thiết bị.

Vì vậy, kết quả của nghiên cứu là cơ sở mang tính khoa học, có thể áp dụng trong thực tế sản xuất, hiệu quả cao nhất đạt được khi không có các yếu tố phát sinh làm gián đoạn, ảnh hưởng đến chi phí thời gian thực hiện các công đoạn sản xuất của lò chợ.

\section{Đóng góp của các tác giả}

Đỗ Hoàng Hiệp hình thành ý tưởng, cấu trúc bài báo, hoàn thiện bản thảo cuối cùng; Bùi Mạnh Tùng, Vũ Thái Tiến Dũng và Trần Tuấn Anh thu thập số liệu, xử lý số liệu và tham gia hoàn thiện bản thảo bài báo.

\section{Tài liệu tham khảo}

Công ty than Dương Huy - TKV, (2020). Báo cáo kết quả hoạt động sản xuất kinh doanh năm 2019.

Dung Tien Le, Tung Manh Bui, Hung Duc Pham, Tien Trung Vu, Chi Van Dao, (2018). A modelling technique for top coal fall ahead of face support in mechanised longwall using Discrete Element Method. Journal of Mining and Earth Sciences, 59(6), 56 - 65.

Joachim Pielot, (2006). Maximization of Production in Technological System of Coal Preparation Process. IFAC Proceedings, 39(22), 193 - 198.

Lê Duy Khánh, (2019). Thành lập biểu đồ tổ chức chu kỳ sản xuất hợp lý tại các lò chợ cơ giới hóa của công ty Cổ phần than Hà Lầm - Vinacomin. Luận văn thạc sỹ kỹ thuật, Đại học Mỏ - Địa chất.

Rakesh Kumar, Arun Kumar Singh, Arvind Kumar Mishra and Rajendra Singh, (2015). Underground mining of thick coal seams. International Journal of Mining Science and Technology, 25(6), 885 - 896.

Syd S. Peng, Feng Du, Jingyi Cheng and Yang Li, (2019). Automation in U.S. longwall coal mining: A stateoftheart review. International Journal of Mining Science and Technology, 29(2), 151 - 159.

Victor V. Okolnishnikov, Sergey S. Rudometov and Sergey S. Zhuravlev, (2013). Simulation of Technological Processes in Coal Mining. IFAC Proceedings Volumes, 46(9), 2173 - 2178.

Yun, Q. X., Guo, W. W., Chen, Y.F., Lu, C. W. and Lian, M. J., (2003). Evolutionary algorithms for the optimization of production planning in underground mines. Application of Computers and Operations Research in the Minerals Industries, 311 - 314. 